\title{
Alternative transmission routes in the malaria elimination era: an overview of transfusion-transmitted malaria in the Americas
}

Regina M. Alho 1,2, Kim Vinícius Amaral Machado ${ }^{3}$, Fernando F. A. Val ${ }^{1,3}$, Nelson A. Fraiji ${ }^{2}$, Marcia A. A. Alexandre ${ }^{1}$, Gisely C. Melo ${ }^{1,3}$, Judith Recht ${ }^{4}$, André M. Siqueira ${ }^{5}$, Wuelton M. Monteiro ${ }^{1,3^{*}}$ and Marcus V. G. Lacerda ${ }^{1,3,6}$

\begin{abstract}
Background: Transfusion-transmitted (TT) malaria is an alternative infection route that has gained little attention from authorities, despite representing a life-threatening condition. There has been no systematic review of this health problem in American countries. The aim of this study was to describe the clinical and epidemiological characteristics of TT malaria in the Americas and identify factors associated with lethality based on the studies published in the literature.

Methods: Potentially relevant papers in all languages were retrieved from MEDLINE and LILACS. Additional articles were obtained from reviews and original papers. Publications on screening of candidate blood donors and on surveillance of TT malaria cases were included. Odds ratios with respective $95 \%$ confidence intervals $(95 \% \mathrm{Cl})$ were calculated. Epidemiological characteristics of blood donors of TT malaria cases, including a pooled positivity of different tests for malaria diagnosis, were retrieved.

Results: A total of 63 publications regarding TT malaria from seven countries were included, from 1971 to 2016. A total of 422 cases of TT malaria were recorded. Most TT malaria cases were in females (62.0\%) and 39.5\% were in the $\geq 61$ years-old age group. About half of all cases were from Mexico (50.7\%), 40.3\% from the United States of America (USA) and 6.6\% from Brazil. Gyneco-obstetrical conditions (67.3\%), surgical procedures (20.6\%) and complications from neoplasias (6.1\%) were the most common indications of transfusion. Packed red blood cells (RBCs) (50.7\%) and whole blood (43.3\%) were the blood products mostly associated with TT malaria. Cases were mostly caused by Plasmodium malariae (58.4\%), followed by Plasmodium vivax (20.7\%) and Plasmodium falciparum (17.9\%). A total of 66.6\% of cases were diagnosed by microscopy. Incubation period of 2-3 weeks was the most commonly observed (28.6\%). Lethality was seen in $5.3 \%$ of cases and was associated with living in non-endemic countries, P. falciparum infection and concomitant neoplastic diseases.
\end{abstract}

Conclusion: There is an important research and knowledge gap regarding the TT malaria burden in Latin American countries where malaria remains endemic. No screening method that is practical, affordable and suitably sensitive is available at blood banks in Latin American countries, where infections with low parasitaemia contribute greatly to transmission. Lethality from TT malaria was not negligible. TT malaria needs to be acknowledged and addressed in areas moving toward elimination.

Keywords: Malaria, Plasmodium, Blood transfusion, Transfusion-transmitted malaria

\footnotetext{
*Correspondence: wueltonmm@gmail.com

1 Universidade do Estado do Amazonas, Av. Pedro Teixeira, 25, Dom Pedro,

Manaus, AM 69040-000, Brazil

Full list of author information is available at the end of the article
} 


\section{Background}

Malaria is an infectious disease caused by parasites of the genus Plasmodium that is characterized by a potentially fatal acute febrile illness. It is considered a great public health problem worldwide. According to the World Health Organization (WHO), about 3.2 billion people were at risk of developing malaria globally in 2015, with 212 million new cases and 429,000 deaths estimated [1]. Malaria transmission is widespread, with cases concentrated mostly in tropical and sub-tropical areas, mainly in Central and South America and in Southeast Asia for Plasmodium vivax [2] and in Africa for Plasmodium falciparum [3]. Clinically, malaria can manifest with severe symptoms, which can evolve to lethal cases, or present as asymptomatic infections. The latter are particularly challenging in non-endemic settings and those approaching elimination, as asymptomatic Plasmodium parasites in low densities are still able to transmit infection but less likely to be diagnosed.

In the Americas, the population at risk for malaria exceeds 120 million in over 21 countries, with $P$. vivax infections accounting for more than $70 \%$ of reported cases [1]. Only five countries in this region have higher than $40 \%$ P. falciparum infection rate (Haiti, Dominician Republic, Guyana, French Guiana, Suriname). Out of 390,000 confirmed cases in the Americas in 2015, three countries were responsible for more than 75\%: Brazil (37\%), Venezuela (23\%) and Colombia (17\%) [1]. In Brazil, malaria transmission is mainly restricted to the Amazon region with $99.8 \%$ of all reported cases, of which $83 \%$ are $P$. vivax malaria [4]. Despite an $80 \%$ decline in mortality over the past 15 years, 79 malaria-related deaths were reported in the Americas [1]. Interestingly, the highest lethality is seen outside the endemic regions, where a higher proportion of $P$. falciparum combined with late diagnosis may lead to higher rates of complications [5].

The natural malaria transmission occurs through the blood meal bite of the female Anopheles mosquito, although infection may also occur congenitally or accidentally, through infected blood transfusion. Transfusion-transmitted (TT) malaria is an alternative infection route that has gained little attention from authorities, despite presenting real danger to patients. Subjects requiring blood transfusion are a vulnerable population in debilitating conditions. Vivax malaria was traditionally considered a benign disease with no associated severe cases. Recent data however, have shown that vivax malaria may result in severe disease and death [68] including in the Americas [10-14]. The Brazilian Ministry of Health has shown that although the number of hospitalizations and severe cases in Brazil has decreased in recent years, deaths due to malaria infection still occur, with a total of 60 deaths in 2012 and 41 in 2013 [9]. A case series of autopsies in which $P$. vivax was considered a causative agent or a contributing factor for death showed that 13 out of 17 patients presented co-morbidities [15].

Blood banks usually perform a screen of donor candidates' health before blood donation, including current infections and a detailed history of previous diseases and travel. The criteria for this haemovigilance are defined by each country through their national regulation agencies. In Brazil, policies regarding blood donation differ between malaria endemic and non-endemic regions. In non-endemic areas, candidates will not be accepted as donors if they have been to endemic areas within the previous 6 months or had malaria in the previous 3 years, while in areas with active malaria transmission, the presence of Plasmodium or plasmodial antigens must be tested $[16,17]$. A recent study in the Amazon region, that evaluated ten blood banks regarding infrastructure and procedures relative to TT malaria, found that none was classified as 'adequate', highlighting an urgent need to call attention to this challenge and work towards better standardization and regulation compliance regarding TT malaria by authorities [18]. Furthermore, as most malaria-infected blood donors are asymptomatic, both the use of clinical and epidemiological criteria as well as microscopy and rapid diagnostic tests (RDTs) are potentially insufficient for malaria screening. These asymptomatic infections characterized by low parasite densities require more sensitive methods for detection [19]. Although cases of TT malaria are assumed based on different criteria, transmission can only be proven definitely by genotyping. However, most cases in the literature are "presumed" cases, where genotyping was not done or reported.

The primary objective of this study was to describe epidemiological characteristics of TT malaria in the Americas through a systematic review. Secondary objectives included description of donor epidemiology characteristics, donor selection process in malaria endemic and non-endemic regions, diagnostic methods used in donor screening, and demographical, clinical and laboratory characteristics of TT malaria.

\section{Methods}

A systematic review was conducted of all available articles regarding TT malaria in countries of the Americas. Potentially relevant articles in English, Spanish and Portuguese were accessed from MEDLINE and LILACS to review their full texts. A free text search using the combination of Medical Subject Heading (MeSH) terms and keywords was utilized (Table 1). Only original research was included. Studies were eligible for inclusion if they reported any information on TT malaria in subjects 
Table 1 Keywords and MESH headings used for literature searches

\begin{tabular}{ll}
\hline Database & Search strategy \\
\hline LILACS & (Transfusion) AND (malaria OR plasmodium) \\
Medline & (Transfusion) AND (malaria OR plasmodium) AND (Antilles OR Latin America OR South America OR Central America OR Caribbean OR \\
& Anguilla OR Antigua OR Aruba OR Barbuda OR Argentina OR Bahamas OR Barbados OR Belize OR Bolivia OR Brazil OR Chile OR Colom- \\
& bia OR Costa Rica OR Dominica OR Dominican Republic OR Ecuador OR El Salvador OR Grenada OR Grenadines OR Guadeloupe OR \\
& Guatemala OR Guyana OR Haiti OR Honduras OR Jamaica OR Martinique OR Mexico OR Montserrat OR Nevis OR Nicaragua OR Panama \\
& OR Paraguay OR Peru OR Puerto Rico OR Saint Kitts OR Saint Lucia OR Saint Vincent OR Suriname OR Surinam OR Trinidad OR Tobago \\
& OR Uruguay OR Venezuela OR North America OR USA OR Canada) \\
\hline
\end{tabular}

living in American countries. An individual was considered to have malaria if they presented with a positive diagnostic test, such as microscopy, direct serology, RDT, or DNA amplification tests. Moreover, positive indirect serology was considered a marker of lifetime Plasmodium infection [4]. After eliminating duplicates, relevant papers were identified by screening titles and abstracts. Two independent investigators performed the selection, with disagreements being included after consensus was reached. Citation tracking of reviews and original papers resulted in inclusion of additional articles. Data were extracted by filling out a template with study area, study design, participant characteristics, number of cases, diagnostic methods, and Plasmodium species. Afterwards, articles were classified in the following categories:

\section{Epidemiological screening of candidate blood donors}

Cross-sectional information from donations deferral based on epidemiological history was collected, including country and city of the study, time period, subjects characteristics, sample size, and deferral causes and rates.

\section{Laboratorial screening of candidate blood donors}

Plasmodium infection prevalences were collected from different study areas, including sample size and characteristics, laboratory method employed and prevalence rates by species.

\section{Case reports of TT malaria}

In this category, data extraction was performed at individual level to identify the profile of TT malaria cases, including country of the report, gender, age, transfusion indication, blood product associated with $\mathrm{TT}$ malaria, Plasmodium species, method employed for malaria diagnosis, incubation period, and signs and symptoms presented by the patient.

Proportions of deaths from the pooled TT malaria cases were compared by Chi square test (corrected by Fisher's test if needed), using living in an endemic country, gender, age group, transfusion indication, blood product associated with TT malaria, Plasmodium species, and incubation period as independent variables.
Odds ratio (OR) with its 95\% confidence interval (95\% CI) was calculated for each association. Where zeros caused problems with computation of the OR and 95\% CI, 0.5 was added to all cells $[20,21]$. Statistical analysis was performed using STATA package version 14.1 (Stata Corp. 2013).

Epidemiological characteristics of blood donors of TT malaria cases were retrieved, including gender, age, history of living or travelling to endemic areas, probable site of infection, history of previous episodes of malaria, Plasmodium species found and detection methods evidencing Plasmodium infection. Positivities of different tests for malaria diagnosis in blood donors were presented.

\section{Results \\ Study characteristics}

An initial database search returned 257 records from MEDLINE and 50 from LILACS. After duplicate removal, 293 studies were assessed for inclusion criteria compliance. Screening by titles and abstracts revealed 68 potential inclusions. After full text reading, 30 articles were removed. Finally, 25 additional records were identified through manual search of reference lists. A total of 63 records referred to TT malaria in the Americas and were retrieved for inclusion (Fig. 1). From these, 53\% (34) were from the United States of America (USA), 18\% (11) from Brazil, 8\% (five) from Canada, $8 \%$ (five) from Venezuela, $6 \%$ (four) from Colombia, 5\% (three) from Mexico, and $2 \%$ (one) from Peru. A total of 11 studies of epidemiological screening of candidate blood donors, 15 studies of laboratorial screening of candidate blood donors and 41 studies reporting TT malaria cases were retrieved.

\section{Candidate blood donor malaria-related deferrals}

Donor selection based on clinical and epidemiological profile was described in 11 records, with five from the USA, three from Canada, two from Brazil, and one from Colombia [22-32] (Table 2). In general, travel or residence in malaria-endemic countries, irrespective of time, were considered as deferral causes in non-endemic countries. In the USA, data indicated a national deferral rate of $1.1 \%$ due to presumed malaria exposure of among 


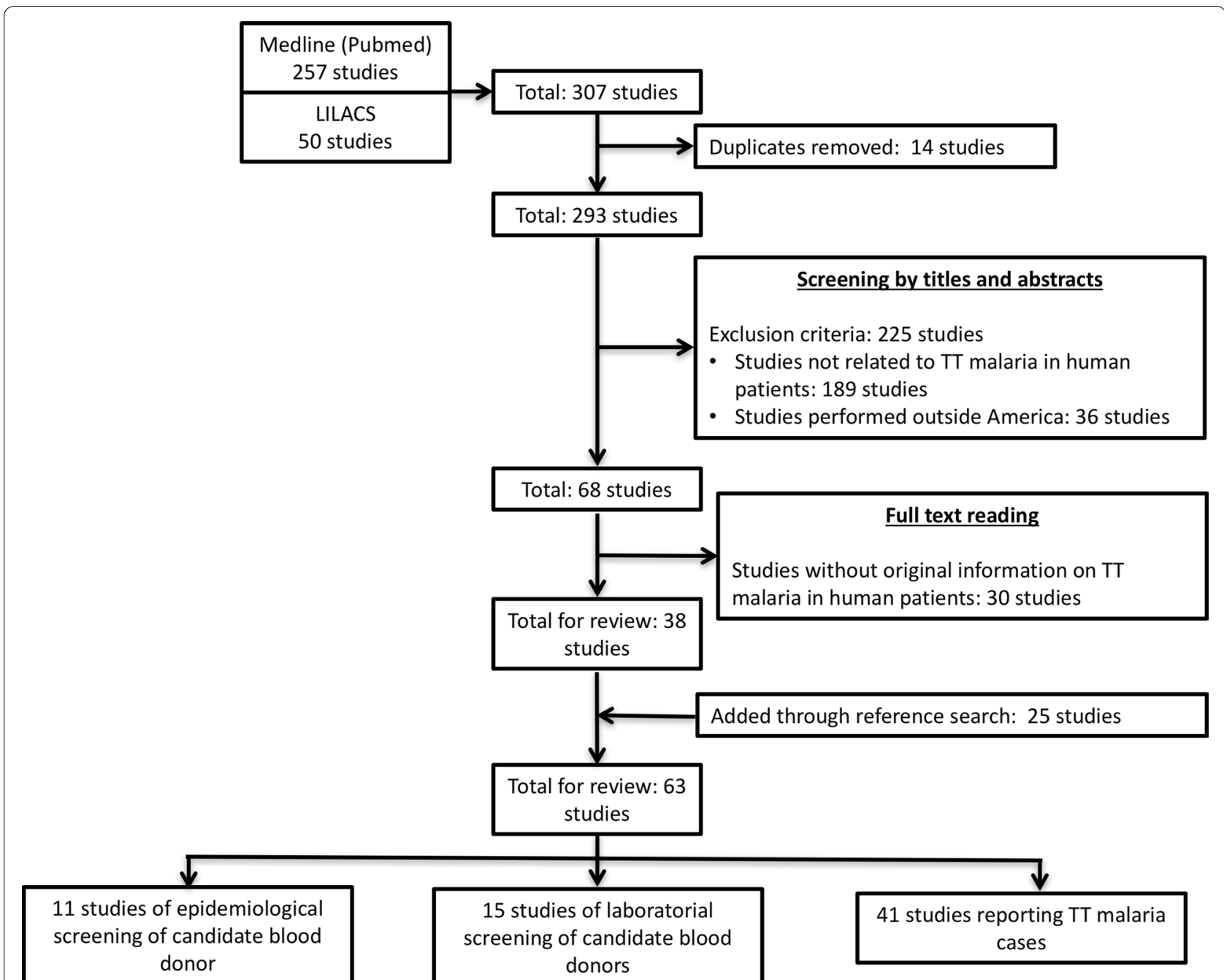

Fig. 1 Flow chart of inclusion. Four articles presented more than one type of study category

28,933,936 candidate blood donors, from 2000 to 2006 [24], although rates varied between States. In 2006, travel to malaria-endemic countries was responsible for $16.2 \%$ of deferrals of blood donors in six blood centres located in San Francisco, Milwaukee, Cincinnati, Pittsburgh, Dedham, and Douglasville [30]. Of this group, $42 \%$ were deferred due to travel to low-risk malaria regions in Mexico [31]. In Canada, 7216 donations were deferred due to travel to malaria-endemic countries in 2002 [28]. Nationwide data from Canada estimated a deferral rate of 3\% among candidate donors from July to December 2004 [25] and of 4.7\% among candidate donors from 2007 to 2012 [26].

Malaria deferral practices were not consistent among endemic countries (Table 2). In Brazil, previous history of malaria, travel to endemic areas without prophylaxis in the last 6 months, living in malaria-endemic areas, travel to endemic area in the last 6 months, and previous malaria in the last year or fever in the last 30 days were considered as deferral causes, depending on the location where the candidate was tested [27, 32]. In São Paulo, a non-endemic area, subjects with history of travel to endemic areas without prophylaxis in the last 6 months, living in malaria-endemic areas (deferral for 3 years) and previous malaria were considered non-eligible for blood donations, resulting in a $3 \%$ deferral rate [27]. In malaria-endemic areas of the Brazilian Amazon, deferral donation rates ranged from no deferrals among 31 candidates in the State of Mato Grosso, using fever in the last 30 days as the deferral reason in a hyperendemic area [27], to $11.7 \%$ in Manaus where all candidates reporting a previous episode of malaria were deferred [32]. In one report from Colombia, travel or living in endemic areas in the last year was considered as a deferral cause, resulting in a deferral rate in Cali of 40.2\% (115) in 2002 in a group of 286 candidate donors [22]. 


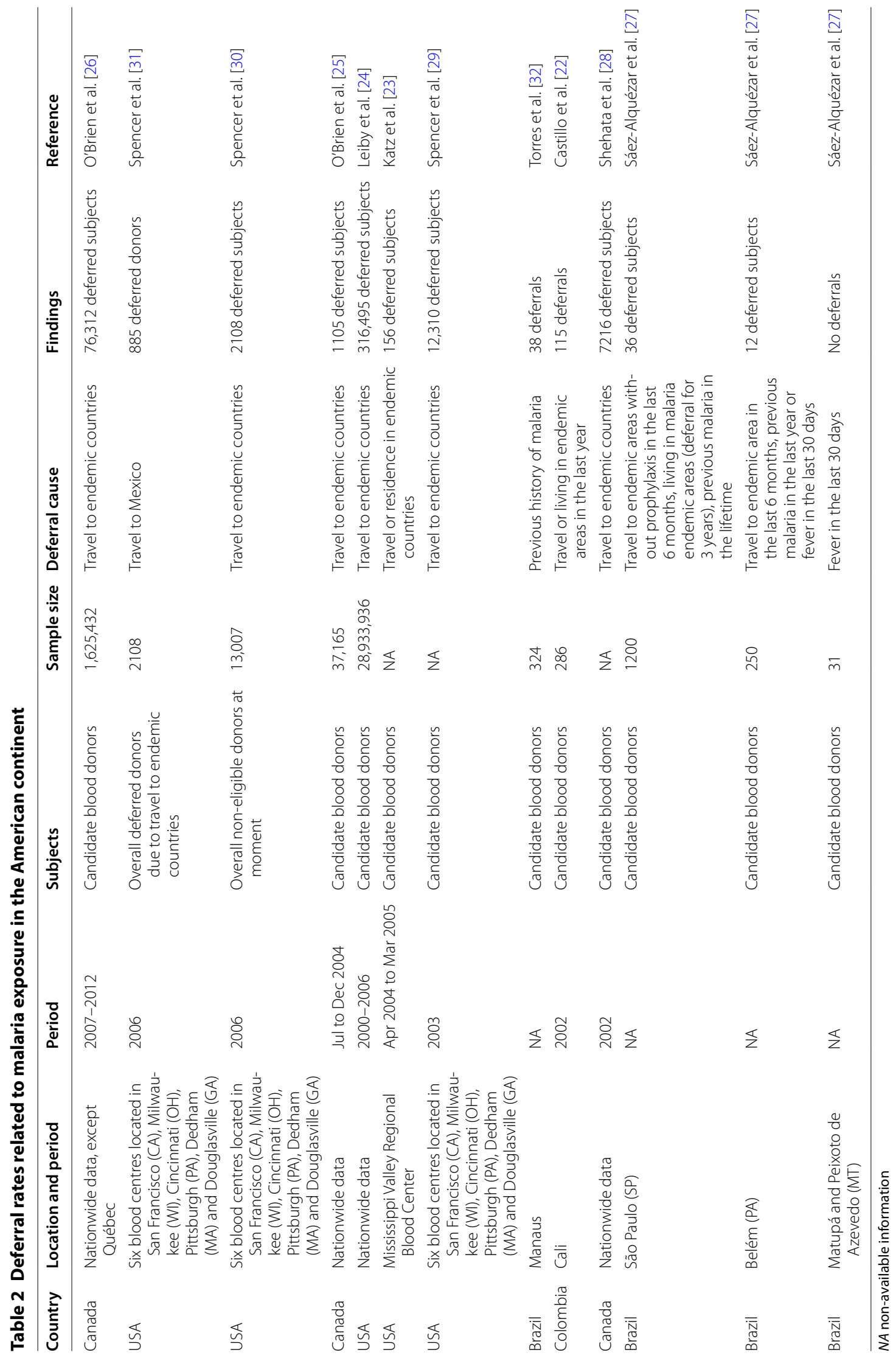




\section{Plasmodium screening of candidate blood donors}

Laboratory testing of blood donors (12,370 subjects), deferred donors (5696 subjects) or blood donors suspected to be responsible for TT malaria cases (47 subjects) was shown in 15 studies from Brazil (nine locations), USA (two locations), Venezuela (six locations), and Colombia (two locations) (Table 3). Among selected blood donors, microscopy was used for screening in seven locations, all with negative results. RDT was used in only one study, with no infections detected [33]. PCR was used for donor screening in nine locations, with results ranging from $0.0 \%$ in Cali (Colombia) [22] and USA donors [34] to $7.5 \%$ in São Paulo [35]. Compared to microscopy, PCR presented higher positivity in one study [32] and total agreement in another [36]. Quantitative buffy coat was employed in two studies with no cases detected [27, 32]. Direct serological tests presented prevalences of $0.0 \%$ in São Paulo, Pará and Mato Grosso states (Brazil) [27] and Cali (Colombia) [22] and $2.4 \%$ in Venezuela [36]. In endemic countries, indirect serological tests showed prevalences ranging from $0 \%$ in hypoendemic areas of Colombia [22] and Venezuela [37] to $64.5 \%$ among blood donors of Mato Grosso (Brazil) [27]. In general, serological screening using indirect methods showed circulating anti-Plasmodium antibodies with prevalences around 1-2\% in non-endemic or hypoendemic areas of Latin America [27, 37-39] and higher than $10 \%$ in malaria-endemic areas [27, 40, 41]. High prevalences of both $P$. falciparum and $P$. vivax antibodies in endemic areas were found with these methods $[27,41]$.

In Brazil, reports using PCR showed P. falciparum infections in 5.1\% of São Paulo blood donors [35], whereas $P$. vivax was found in $2.3 \%$ of blood donors in São Paulo [35], 1.3\% of blood donors in Belém [42], and $0.3 \%$ of blood donors in Manaus [32]; mixed P. falciparum-P. vivax infections were found in five locations [35, 43]. Among malaria-deferred blood donations, microscopy and PCR tested negative for all samples in the USA [34] and Brazil [32]. Quantitative buffy coat was positive in a sample from Manaus for which PCR was negative [32]. Direct serological tests were negative in São Paulo and Pará states (Brazil) [27]. Indirect serological tests showed a prevalence of $1.6 \%$ among 5610 malariadeferred donors in the USA [34].

In the USA, blood donors suspected to be sources for TT malaria cases tested positive for P. falciparum (12.8\%) and $P$. malariae (6.3\%) using indirect serology [44].

\section{Epidemiological and clinical profile of TT malaria patients}

This systematic review retrieved 422 cases of TT malaria (Table 4). Cases were mostly reported from Mexico (214 cases; $50.7 \%$ ), the USA (170 cases; $40.3 \%$ ) and Brazil (28 cases; $6.6 \%)$. Most cases were female (62.0\%) or belonged to the group age $\geq 61$ years old (39.5\%). Gyneco-obstetrical conditions (67.3\%), surgical procedures (20.6\%) and complications from neoplasias (6.1\%) were the most common indications of transfusion. Packed red blood cells (RBCs) (50.7\%), whole blood (43.3\%) and platelets (6.0\%) were the blood products associated with TT malaria. Cases were mostly caused by $P$. malariae (58.4\%), P. vivax (20.7\%) and P. falciparum (17.9\%). A total of $66.6 \%$ of the cases were diagnosed by microscopy and $30.6 \%$ by microscopy plus indirect immunofluorescence (IIF). The incubation period was reported in only $10 \%$ of all cases, from which $2-3$ weeks was the most frequent $(28.6 \%)$, with $61.9 \%$ of cases showing an incubation period of 2-5 weeks.

Fever (99.3\%) and chills (69.2\%) were the most common signs of malaria presented by the TT malaria cases. Signs and symptoms of severe malaria, such as haemoglobin drop, jaundice, convulsions, hypotension, renal failure, respiratory failure, and disseminated intravascular coagulation were also reported. Lethality was 5.3\%.

\section{Risk factors for lethality among TT malaria patients}

Living in an endemic country was associated with a lower odd of lethality from TT malaria [OR 0.19 (95\% CI 0.060.54); ( $=0.002)$ ]. Regarding background conditions, neoplasias were associated with a higher odd of lethality from TT malaria in comparison with other transfusion indications [OR $0.02(95 \% \mathrm{CI}<0.01-0.51) ;(\mathrm{p}=0.018)]$. Plasmodium falciparum malaria was associated with a higher risk of lethality in comparison with $P$. malariae [OR 6.72 (95\% CI 2.36-19.13); ( $<$ 0.001)] and P. vivax [OR 7.26 (95\% CI 1.49-35.41); $(\mathrm{p}=0.014)$ ]. Gender, age, blood product received and incubation period were not associated with lethality from TT malaria (Table 5).

\section{Characteristics of donors identified as responsible for TT malaria cases}

Epidemiological characteristics of 163 blood donors identified as responsible for TT malaria cases are presented in Table 6. Completeness of individual information ranged from $10.4 \%$ for age to $82.2 \%$ for method evidencing Plasmodium infection. Blood donors were mostly male (81.6\%) and between 21 and 30 years old (52.9\%). History of living or travelling to endemic areas was reported by $96.8 \%$ of the donors. Probable site of infection was reported mostly as Sub-Saharan Africa (61.0\%), including Nigeria (18.6\%), Ghana (10.2\%) and Liberia (10.2\%). Latin American countries were identified as the probable site of infection for $15.3 \%$ of the donors: Central American countries (5.1\%), the Brazilian Atlantic coast (3.4\%) and Mexico (3.4\%). Mediterranean countries $(11.9 \%)$, Vietnam $(8.5 \%)$ and India (3.4\%) were also identified as probable sites of infection. History of previous 
Table 3 Malaria prevalence in candidate blood donors in the American continent

\begin{tabular}{|c|c|c|c|c|c|}
\hline Study area & $\begin{array}{l}\text { Sample size and fea- } \\
\text { tures }\end{array}$ & Detection method & Prevalence (\%) & $\begin{array}{l}\text { Prevalence by species } \\
\text { (\%) }\end{array}$ & Reference \\
\hline \multirow[t]{2}{*}{ Manaus, Brazil } & \multirow[t]{2}{*}{407 blood donors } & Microscopy & 0.0 & - & \multirow[t]{2}{*}{ Torres et al. [33] } \\
\hline & & $\mathrm{RDT}$ & 0.0 & - & \\
\hline \multirow[t]{3}{*}{ São Paulo, Brazil } & \multirow[t]{3}{*}{1108 blood donors } & \multirow[t]{3}{*}{ PCR } & \multirow[t]{3}{*}{7.5} & P. falciparum (5.1) & \multirow[t]{3}{*}{ Maselli et al. [35] } \\
\hline & & & & P. vivax (2.3) & \\
\hline & & & & $\begin{array}{l}\text { Mixed } P \text {. falciparum-P. } \\
\text { vivax infection }(0.1)\end{array}$ & \\
\hline \multirow[t]{2}{*}{ USA } & \multirow{2}{*}{$\begin{array}{l}5610 \text { malaria-deferred } \\
\text { donors }\end{array}$} & EIA & 1.6 & NA & \multirow[t]{2}{*}{ Nguyen et al. [34] } \\
\hline & & PCR & 0.0 & - & \\
\hline Pará, Brazil & 595 blood donors & PCR & 1.3 & P. vivax (1.3) & $\begin{array}{l}\text { Batista-dos-Santos et al. } \\
\text { [42] }\end{array}$ \\
\hline \multirow{3}{*}{$\begin{array}{l}\text { Caracas, Ciudad Bolívar, } \\
\text { Puerto Ayacucho and } \\
\text { Cumaná, Venezuela }\end{array}$} & \multirow[t]{3}{*}{762 blood donors } & Direct EIA & 2.4 & NA & \multirow[t]{3}{*}{ Contreras et al. [36] } \\
\hline & & Microscopy & 0.0 & - & \\
\hline & & PCR & 0.0 & - & \\
\hline Porto Velho (RO), Brazil & 100 blood donors & PCR & 3.0 & $\begin{array}{l}\text { Mixed } P \text {. falciparum-P. } \\
\text { vivax infection ( } 2.3)\end{array}$ & Fugikaha et al. [43] \\
\hline Macapá (AP), Brazil & 100 blood donors & PCR & 3.0 & $\begin{array}{l}\text { Mixed } P \text {. falciparum-P. } \\
\text { vivax infection ( } 2.3)\end{array}$ & \\
\hline Belém (PA), Brazil & 100 blood donors & PCR & 2.0 & $\begin{array}{l}\text { Mixed } P \text {. falciparum-P. } \\
\text { vivax infection ( } 2.3)\end{array}$ & \\
\hline Rio Branco (AC), Brazil & 100 blood donors & PCR & 1.0 & $\begin{array}{l}\text { Mixed } P \text {. falciparum-P. } \\
\text { vivax infection ( } 2.3)\end{array}$ & \\
\hline \multirow[t]{3}{*}{ Manaus (AM), Brazil } & \multirow[t]{3}{*}{286 blood donors } & Microscopy & 0.0 & - & \multirow[t]{3}{*}{ Torres et al. [32] } \\
\hline & & QBC & 0.0 & - & \\
\hline & & PCR & 0.3 & P. vivax (0.3) & \\
\hline \multirow[t]{3}{*}{ Manaus (AM), Brazil } & \multirow[t]{3}{*}{38 deferred donations } & Microscopy & 0.0 & - & \multirow[t]{3}{*}{ Torres et al. [32] } \\
\hline & & $\mathrm{QBC}$ & 1.4 & NA & \\
\hline & & $P C R$ & 0.0 & - & \\
\hline \multirow[t]{2}{*}{ Caracas, Venezuela } & \multirow[t]{2}{*}{500 blood donors } & IIF (IgG Pf) & 0.8 & P. falciparum (0.8) & \multirow[t]{2}{*}{ Contreras et al. [39] } \\
\hline & & ELISA (IgG Pf) & 0.8 & P. falciparum (0.8) & \\
\hline \multirow[t]{2}{*}{ Ciudad Bolívar, Venezuela } & \multirow[t]{2}{*}{500 blood donors } & IIF (lgG Pf) & 3.8 & P. falciparum (3.8) & \multirow[t]{2}{*}{ Contreras et al. [39] } \\
\hline & & ELISA (IgG Pf) & 2.0 & P. falciparum (2.0) & \\
\hline Cali, Colombia & 286 blood donors & Microscopy & 0.0 & - & Castillo and Ramírez [22] \\
\hline & & EIA lgG & 0.0 & - & \\
\hline & & EIA HRPII & 0.0 & - & \\
\hline & & PCR & 0.0 & - & \\
\hline São Paulo (SP), Brazil & 1164 blood donors & Microscopy & 0.0 & - & Sáez-Alquézar et al. [27] \\
\hline & & DIF & 0.0 & - & \\
\hline & & IIF IgG anti-Pv & - & P. vivax (1.2) & \\
\hline & & IIF IgG anti-Pf & - & P. falciparum (0.9) & \\
\hline & & ELISA IgG Pf & - & P. falciparum (1.0) & \\
\hline & 36 deferred donations & Microscopy & 0.0 & - & \\
\hline & & DIF & 0.0 & - & \\
\hline & & IIF IgG anti-Pv & - & P. vivax (16.7) & \\
\hline & & IIF IgG anti-Pf & - & P. falciparum (5.6) & \\
\hline & & ELISA IgG Pf & - & P. falciparum (2.7) & \\
\hline
\end{tabular}


Table 3 continued

\begin{tabular}{|c|c|c|c|c|c|}
\hline Study area & $\begin{array}{l}\text { Sample size and fea- } \\
\text { tures }\end{array}$ & Detection method & Prevalence (\%) & $\begin{array}{l}\text { Prevalence by species } \\
\text { (\%) }\end{array}$ & Reference \\
\hline \multirow[t]{12}{*}{ Belém (PA), Brazil } & \multirow[t]{6}{*}{238 blood donors } & Microscopy & 0.0 & - & \multirow[t]{12}{*}{ Sáez-Alquézar et al. [27] } \\
\hline & & $\mathrm{QBC}$ & 0.0 & - & \\
\hline & & DIF & 0.0 & - & \\
\hline & & IIF IgG anti-Pv & - & P. vivax (9.6) & \\
\hline & & IIF IgG anti-Pf & - & P. falciparum (10.1) & \\
\hline & & ELISA IgG Pf & & P. falciparum (17.2) & \\
\hline & \multirow[t]{6}{*}{12 deferred donations } & Microscopy & 0.0 & - & \\
\hline & & $\mathrm{QBC}$ & 0.0 & - & \\
\hline & & DIF & 0.0 & - & \\
\hline & & IIF IgG anti-Pv & - & P. vivax (25.0) & \\
\hline & & IIF IgG anti-Pf & - & P. falciparum (41.6) & \\
\hline & & ELISA IgG Pf & & P. falciparum (25.0) & \\
\hline \multirow{5}{*}{$\begin{array}{l}\text { Matupá and Peixoto de } \\
\text { Azevedo (MT), Brazil }\end{array}$} & \multirow[t]{5}{*}{31 blood donors } & Microscopy & 0.0 & - & \\
\hline & & DIF & 0.0 & - & \\
\hline & & $\| F$ IgG anti-Pv & - & P. vivax (74.2) & \\
\hline & & IIF IgG anti-Pf & - & P. falciparum (64.5) & \\
\hline & & ELISA IgG Pf & - & P. falciparum (54.8) & \\
\hline \multirow[t]{4}{*}{ Porto Velho (RO), Brazil } & \multirow[t]{4}{*}{230 blood donors } & IIF IgG Pf & - & P. falciparum (32.0) & \multirow[t]{4}{*}{ Ferreira et al. [41] } \\
\hline & & IIF IgG PV & - & P. vivax (24.0) & \\
\hline & & IIF IgM Pf & - & P. falciparum (4.0) & \\
\hline & & IIF IgM Pv & - & P. vivax (1.0) & \\
\hline Caracas (DF), Venezuela & 426 blood donors & ElA lgG Pf & - & P. falciparum (0.0) & Nunez et al. [37] \\
\hline $\begin{array}{l}\text { Cumaná (Sucre), Ven- } \\
\text { ezuela }\end{array}$ & 120 blood donors & EIA IgG Pf & - & P. falciparum (2.5) & Nunez et al. [37] \\
\hline $\begin{array}{l}\text { Barcelona (Anzoátegui), } \\
\text { Venezuela }\end{array}$ & 285 blood donors & EIA IgG Pf & - & P. falciparum (0.7) & Nunez et al. [37] \\
\hline $\begin{array}{l}\text { San Fernando (Apure), } \\
\text { Venezuela }\end{array}$ & 59 blood donors & ElA IgG Pf & - & P. falciparum (1.7) & Nunez et al. [37] \\
\hline Cali, Colombia & 1859 blood donors & ElA IgG Pf & - & P. falciparum (13.4) & de Morales et al. [40] \\
\hline Bogotá, Colombia & 3114 blood donors & EIA IgG Pf & - & P. falciparum (0.9) & $\begin{array}{l}\text { de Morales and Espinal } \\
\text { [38] }\end{array}$ \\
\hline \multirow[t]{3}{*}{ USA } & \multirow{3}{*}{$\begin{array}{l}47 \text { (from 117) blood } \\
\text { donors suspected to be } \\
\text { responsible for 10 TTM } \\
\text { cases }\end{array}$} & \multirow[t]{3}{*}{ IIF Ig anti-Pf+Pv+Pm } & \multirow[t]{3}{*}{19.1} & P. falciparum (12.8) & \multirow[t]{3}{*}{ Sulzer and Wilson [44] } \\
\hline & & & & P. malariae (6.3) & \\
\hline & & & & P. vivax (0.0) & \\
\hline
\end{tabular}

DIF direct immunofluorescence, EIA enzyme immunoassay, IIF indirect immunofluorescence, $N A$ non-available information, $P C R$ polymerase chain reaction, $Q B C$ quantitative buffy coat, RDT rapid diagnostic test, USA United States of America

episodes of malaria was reported for $33.3 \%$ of the donors. Plasmodium species found in donors were mostly P. falciparum (43.1\%), P. malariae (27.7\%) and P. vivax (23.1\%). A total of $49.3 \%$ of donors were diagnosed by IIF alone and $33.6 \%$ by microscopy plus IIF.

Positivities of PCR, microscopy and IIF for malaria diagnosis in blood donors were 73.3, 79.7 and 100.0\%, respectively. PCR positivity ranged from $62.5 \%$ for $P$. falciparum to $100.0 \%$ for $P$. vivax. Microscopy positivity ranged from $66.7 \%$ for $P$. ovale to $90.0 \%$ for $P$. vivax.

\section{Discussion}

International policies recommend that blood for transfusion should be screened for TT infections, including malaria [45], however these practices vary considerably between countries and regions. Furthermore, there has been a paucity of information concerning the distribution and potential role of different Plasmodium species in transfusion-related malaria cases, and the clinical impact of parasitaemic blood amongst patients with co-morbidities, which most of blood transfusion recipients present 
Table 4 Epidemiological characteristics of 422 transfusion-transmitted malaria cases reported in the American continent

\begin{tabular}{|c|c|c|}
\hline Characteristics & $\begin{array}{l}\text { Number } \\
\text { of cases }\end{array}$ & $\begin{array}{l}\text { Proportion } \\
\text { (\%) }\end{array}$ \\
\hline \multicolumn{3}{|l|}{ Country $(n=422 ;$ completeness $=100.0 \%)$} \\
\hline Mexico & 214 & 50.7 \\
\hline USA & 170 & 40.3 \\
\hline Brazil & 28 & 6.6 \\
\hline Canada & 4 & 0.9 \\
\hline Venezuela & 3 & 0.7 \\
\hline Peru & 2 & 0.5 \\
\hline Colombia & 1 & 0.3 \\
\hline \multicolumn{3}{|l|}{ Gender $(n=355 ;$ completeness $=84.1 \%)$} \\
\hline Female & 220 & 62.0 \\
\hline Male & 135 & 38.0 \\
\hline \multicolumn{3}{|c|}{ Age groups (years) $(n=43 ;$ completeness $=10.2 \%)$} \\
\hline$\leq 5$ & 2 & 4.7 \\
\hline $6-15$ & 2 & 4.7 \\
\hline $16-30$ & 8 & 18.6 \\
\hline $31-45$ & 4 & 9.3 \\
\hline $46-60$ & 10 & 23.2 \\
\hline$\geq 61$ & 17 & 39.5 \\
\hline \multicolumn{3}{|c|}{ Transfusion indication $(n=165 ;$ completeness $=39.1 \%)$} \\
\hline Gyneco-obstetrical conditions & 111 & 67.3 \\
\hline Surgical procedures & 34 & 20.6 \\
\hline Complications from neoplasias & 10 & 6.1 \\
\hline Haemoglobinopathies & 2 & 1.2 \\
\hline Nephropathy-associated anaemia & 2 & 1.2 \\
\hline Other causes of anaemia & 6 & 4.4 \\
\hline \multicolumn{3}{|c|}{ Blood product associated with TTM $(n=150 ;$ completeness $=35.5 \%)$} \\
\hline Packed RBCs & 76 & 50.7 \\
\hline Whole blood & 65 & 43.3 \\
\hline Platelets & 9 & 6.0 \\
\hline \multicolumn{3}{|c|}{ Plasmodium species $(n=392 ;$ completeness $=92.9 \%)$} \\
\hline Plasmodium malariae & 229 & 58.4 \\
\hline Plasmodium vivax & 81 & 20.7 \\
\hline Plasmodium falciparum & 70 & 17.9 \\
\hline Plasmodium ovale & 11 & 2.8 \\
\hline Mixed P. falciparum-P. vivax & 1 & 0.2 \\
\hline \multicolumn{3}{|c|}{$\begin{array}{l}\text { Method(s) employed for malaria diagnosis ( } n=314 \text {; complete- } \\
\text { ness }=74.4 \% \text { ) }\end{array}$} \\
\hline Microscopy & 209 & 66.6 \\
\hline Microscopy plus IIF & 96 & 30.6 \\
\hline Microscopy plus PCR & 5 & 1.6 \\
\hline $\begin{array}{l}\text { Microscopy plus bone marrow aspirate } \\
\text { examination }\end{array}$ & 2 & 0.6 \\
\hline Microscopy plus PCR plus IIF & 1 & 0.3 \\
\hline PCR & 1 & 0.3 \\
\hline \multicolumn{3}{|c|}{ Incubation period (in weeks) $(n=42 ;$ completeness $=10.0 \%)$} \\
\hline$\leq 2$ & 3 & 7.1 \\
\hline $2-3$ & 12 & 28.6 \\
\hline
\end{tabular}

Table 4 continued

\begin{tabular}{lcc}
\hline Characteristics & $\begin{array}{l}\text { Number } \\
\text { of cases }\end{array}$ & $\begin{array}{l}\text { Proportion } \\
\text { (\%) }\end{array}$ \\
\hline $3-4$ & 6 & 14.3 \\
$4-5$ & 8 & 19.0 \\
$5-6$ & 1 & 2.4 \\
$6-7$ & 2 & 4.8 \\
$7-8$ & 7 & 16.7 \\
$>8$ & 3 & 7.1 \\
\hline
\end{tabular}

$R B C s$ red blood cells, IIF indirect immunofluorescence, $P C R$ polymerase chain reaction

[19]. This analysis shows that malaria screening in blood services in the American continent is mainly based on the epidemiological history of the donor. Recent travel or residence in malaria-endemic countries was considered as deferral causes in the USA and Canada. In areas with low odds of donors carrying malaria parasites, exclusion of malaria based on history of recent travel or residence in malaria-endemic countries $[24,26]$ seems a reasonable approach, as it would not greatly impact the amount of blood available for transfusion. In contrast, in some Latin American areas, rejection of malaria-positive donors would jeopardize the blood supply.

In Latin American countries, there is a knowledge gap regarding malaria-deferral practices. In Brazil, previous history of malaria or fever, and travel to or living in endemic areas (with variable time frames), are used as deferral causes. However, evidence-based information is required to guide malaria screening in these areas, especially in those with active malaria transmission, in order to prevent TT malaria and warrant blood availability for transfusion. The wide variation in malaria prevalence in candidate donors from dissimilar endemic areas means that epidemiological and laboratorial screening policies need to be adapted locally. In Brazil, epidemiological screening is based on annual parasite index (API), an indicator not uniform throughout a spatial unit and with considerable changes over time [19]. Strikingly, this screening strategy does not consider that asymptomatic $P$. vivax or $P$. ovale relapses may occur even several months after the primary episode [46]. Cryptic $P$. malariae and P. falciparum infections [47-50] are also clearly related to TT malaria in non-endemic areas from asymptomatic individuals returning years after visiting or living in active transmission settings, as shown here for the Americas and previously in a review of TT $P$. falciparum infections in non-endemic countries in Europe and the Americas (Canada and the USA) [51]. In Latin America, malaria is becoming a disease of peri-urban areas, potentially leading to more donations from Plasmodium carriers [19]. 
Table 5 Factors related to death from transfusion-transmitted malaria in the American continent

\begin{tabular}{|c|c|c|c|c|}
\hline Variable & Death (number, \%) & Discharge (number, \%) & OR $(95 \% \mathrm{Cl})$ & $\mathbf{p}$ \\
\hline \multicolumn{5}{|l|}{ Living in an endemic country } \\
\hline Yes & $5(27.8)$ & $215(67.4)$ & - & 1 \\
\hline No & $13(72.2)$ & $104(32.6)$ & $0.19(0.06-0.54)$ & 0.002 \\
\hline \multicolumn{5}{|l|}{ Sex } \\
\hline Male & $5(83.3)$ & $16(43.2)$ & - & 1 \\
\hline Female & $1(16.7)$ & $21(56.8)$ & $6.56(0.70-61.86)$ & 0.100 \\
\hline \multicolumn{5}{|l|}{ Age group (in years) } \\
\hline$>60$ & $2(50.0)$ & $8(21.6)$ & - & 1 \\
\hline $31-60$ & $2(50.0)$ & $6(16.2)$ & $0.75(0.068-6.96$ & 0.800 \\
\hline $16-30$ & $0(0.0)$ & $7(18.9)$ & $4.41(0.18-107.29)$ & 0.362 \\
\hline$\leq 15$ & $0(0.0)$ & $16(43.2)$ & $9.71(0.42-225.85)$ & 0.157 \\
\hline \multicolumn{5}{|l|}{ Transfusion indication } \\
\hline Gyneco-obstetrical conditions & $0(0.0)$ & $34(49.3)$ & - & 1 \\
\hline Surgical procedures & $5(62.5)$ & $24(34.8)$ & $0.06(0.01-1.22)$ & 0.068 \\
\hline Complications from neoplasias & $2(25.0)$ & $3(4.3)$ & $0.02(<0.01-0.51)$ & 0.018 \\
\hline Haemoglobinopathies & $0(0.0)$ & $2(2.9)$ & $0.07(<0.01-4.48)$ & 0.212 \\
\hline Nephropathy-associated anaemia & $0(0.0)$ & $2(2.9)$ & $0.07(<0.01-4.48)$ & 0.212 \\
\hline Other causes of anaemia & $1(12.5)$ & $4(5.8)$ & $0.04(<0.01-1.24)$ & 0.066 \\
\hline \multicolumn{5}{|c|}{ Blood product associated with TT malaria } \\
\hline Packed RBCs & $7(87.5)$ & $31(86.1)$ & - & 1 \\
\hline Whole blood & $1(12.5)$ & $4(11.1)$ & $0.90(0.09-9.37)$ & 0.932 \\
\hline Platelets & $0(0.0)$ & $1(2.8)$ & $0.71(0.03-19.33)$ & 0.842 \\
\hline \multicolumn{5}{|l|}{ Plasmodium species } \\
\hline Plasmodium falciparum & $9(50.0)$ & $39(12.4)$ & - & 1 \\
\hline Plasmodium malariae & $7(38.9)$ & $204(65.0)$ & $6.72(2.36-19.13)$ & $<0.001$ \\
\hline Plasmodium vivax & $2(11.1)$ & $63(20.1)$ & $7.26(1.49-35.41)$ & 0.014 \\
\hline Plasmodium ovale & $0(0.0)$ & $7(2.2)$ & $3.61(0.19-68.86)$ & 0.394 \\
\hline Mixed P. falciparum-P. vivax & $0(0.0)$ & $1(0.3)$ & $0.72(0.03-19.14)$ & 0.845 \\
\hline \multicolumn{5}{|l|}{ Incubation period (weeks) } \\
\hline$\leq 4$ & 16 (89.9) & 75 (69.4) & - & 1 \\
\hline$>4$ & $2(11.1)$ & $33(30.6)$ & $3.52(0.77-16.19)$ & 0.106 \\
\hline
\end{tabular}

A major concern in TT malaria epidemiology is to estimate the real burden of Plasmodium infection among candidate donors using sensitive detection techniques. Currently there is no available assay to screen blood with low parasitaemia that is sensitive, practical and affordable enough for use by transfusion services [52]. Microscopy is time consuming and certainly not the best diagnostic tool for asymptomatic donors due to its low sensitivity. Rapid diagnostic tests, although faster and reliable, do not offer a substantial improvement in sensitivity compared to microscopy [33].

PCR in donor candidates has shown results ranging from $0 \%$ in Manaus [33] to an unexpected frequency of 7.5\% in São Paulo [35]. The latter finding shall be taken with caution since it is in disagreement with other publications and possibly overestimates the actual risk of malaria transmission by blood transfusion in the city of São Paulo [53]. Pooled analysis showed that PCR did not substantially increase malaria diagnosis in the identified blood donors compared to microscopy. Only one study suggested PCR as a more sensitive tool to detect low parasitaemias in blood donors in the Amazon compared to microscopy [32]. Newer techniques such as nucleic acid testing (NAT) and loop-mediated isothermal amplification (LAMP) would be the best options today in blood banks [54]. Recently, increased PCR diagnostic sensitivity was achieved by targeting multi-copy genomic sequences [55] and by increasing the volume of blood for DNA extraction [56]. Serological markers remain positive for many years after an initial infection, presenting low specificity in endemic areas. Indeed, indirect serological tests showed high prevalences of $P$. falciparum and $P$. vivax 
Table 6 Epidemiological characteristics of 163 blood donors identified as responsible for transfusion-transmitted malaria in the American continent, from 1991 to 2015

\begin{tabular}{|c|c|c|}
\hline Characteristics & $\begin{array}{l}\text { Number } \\
\text { of cases }\end{array}$ & $\begin{array}{l}\text { Proportion } \\
\text { (\%) }\end{array}$ \\
\hline \multicolumn{3}{|l|}{ Sex $(n=103 ;$ completeness $=63.2 \%)$} \\
\hline Male & 84 & 81.6 \\
\hline Female & 19 & 18.4 \\
\hline \multicolumn{3}{|c|}{ Age groups (years) $(n=17$; completeness $=10.4 \%)$} \\
\hline $17-20$ & 6 & 35.3 \\
\hline $21-30$ & 9 & 52.9 \\
\hline$\geq 31$ & 2 & 11.8 \\
\hline \multicolumn{3}{|c|}{$\begin{array}{l}\text { History of living or traveling to endemic areas ( } n=63 \text {; complete- } \\
\text { ness }=38.7 \% \text { ) }\end{array}$} \\
\hline Yes & 61 & 96.8 \\
\hline No & 2 & 3.2 \\
\hline \multicolumn{3}{|c|}{ Probable site of infection $(n=59 ;$ completeness $=36.2 \%)$} \\
\hline Sub-Saharan Africa & 36 & 61.0 \\
\hline Nigeria & 11 & 18.6 \\
\hline Ghana & 6 & 10.2 \\
\hline Liberia & 6 & 10.2 \\
\hline Other Sub-Saharan countries & 13 & 22.0 \\
\hline Latin America & 9 & 15.3 \\
\hline Central American countries & 3 & 5.1 \\
\hline Brazilian Atlantic Coast & 2 & 3.4 \\
\hline Mexico & 2 & 3.4 \\
\hline Colombia & 1 & 1.7 \\
\hline Venezuela & 1 & 1.7 \\
\hline Vietnam & 5 & 8.5 \\
\hline India & 2 & 3.4 \\
\hline Mediterranean countries & 7 & 11.9 \\
\hline Greece & 4 & 6.8 \\
\hline Other Mediterranean countries & 3 & 5.1 \\
\hline \multicolumn{3}{|c|}{ History of previous episodes of malaria $(n=33$; completeness $=20.2 \%)$} \\
\hline Yes & 11 & 33.3 \\
\hline No & 22 & 66.7 \\
\hline \multicolumn{3}{|c|}{ Plasmodium species found ( $n=130 ;$ completeness $=79.8 \%$ ) } \\
\hline Plasmodium falciparum & 56 & 43.1 \\
\hline Plasmodium malariae & 36 & 27.7 \\
\hline Plasmodium vivax & 30 & 23.1 \\
\hline Plasmodium ovale & 7 & 5.4 \\
\hline Mixed P. falciparum-P. vivax & 1 & 0.7 \\
\hline \multicolumn{3}{|c|}{$\begin{array}{l}\text { Method(s) evidencing Plasmodium infection ( } n=134 \text {; complete- } \\
\text { ness }=82.2 \%)\end{array}$} \\
\hline IIF alone & 66 & 49.3 \\
\hline Microscopy plus IIF & 45 & 33.6 \\
\hline Microscopy alone & 11 & 8.2 \\
\hline IIF plus PCR & 5 & 3.7 \\
\hline Microscopy plus IIF plus PCR & 3 & 2.2 \\
\hline PCR alone & 3 & 2.2 \\
\hline $\begin{array}{l}\text { Bone marrow aspirate examination } \\
\text { alone }\end{array}$ & 1 & 0.8 \\
\hline
\end{tabular}

antibodies in malaria-endemic areas, indicating that they are not a good tool for screening donors in those areas $[27,41]$. New epitopes were presented as reasonably good markers of asymptomatic or recently exposed populations [57], but still need to be addressed in blood banks.

In this work, cases were mostly reported from Mexico in the 1970s and 1980s (when this country had a higher malaria incidence) and in the USA. The incidence of TT malaria among people residing in endemic areas is unknown. TT malaria cases misclassification is probably frequent in populations continuously exposed to malaria vectors in the same areas. Furthermore, a proportion of the population in malaria-endemic countries presents asymptomatic parasitaemia, preventing an accurate assessment of whether malaria occurring after transfusion is actually TT malaria [52]. TT malaria surveillance is a challenge in active transmission areas, likely reflected in under-reporting of cases in Central America and Amazon areas. TT malaria can therefore only be distinguished from naturally transmitted cases by genotyping to demonstrate that the parasite in the transfusion recipient is identical to the paired transfused blood unit [58]. A limitation of this approach is that it fails to detect lowlevel Plasmodium clones in the transfused blood.

Transfusion-transmitted malaria prevailed in females requiring blood transfusion after gyneco-obstetrical complications. A significant number of cases were also recorded from the older population, with surgical procedures and complications from neoplasias as the most common transfusion indications. As expected, whole blood and packed RBCs were the most common sources of TT malaria in this study, with $94 \%$ of the total cases reported. Platelets were responsible for $6 \%$ of the TT malaria cases. Previous reports show that platelets, fresh frozen plasma and leukocytes may infrequently transmit malaria [5961]. Separate components, such as plasma and platelets, may contain merozoites or some RBCs contamination, and parasites in such components have been shown to be highly sensitive to pathogen reduction measures, such as photochemical treatment and long-wavelength ultraviolet light (UV) [62]. In Ghana, a randomised, controlled, clinical trial has shown the efficacy and safety of a whole blood pathogen reduction using UV and riboflavin (Mirasol System) at preventing TT malaria [63].

Most TT malaria cases were caused by $P$. malariae. Conversely, $P$. falciparum was the predominant species found in the identified donors. This disagreement may be due to the fact that many blood units or donor samples associated with transfusion $P$. malariae malaria tested negative or positive only by serology. Plasmodium malariae differs from other Plasmodium species by its very low levels of parasitaemia, indolent illness 
and extended duration of asymptomatic infection [50, $64,65]$. Thus, patients generally come to medical attention when a recrudescence is induced by splenectomy performed for reasons unrelated to malaria [66] or when malaria is transmitted by transfusion, as observed in this study. Plasmodium vivax was the second causative agent of TT malaria, mostly related to donors coming from Asia and Latin America, whereas P. falciparum was associated with donors who lived or visited African countries.

Clinical severity of TT malaria is very different in endemic and non-endemic countries. In this work, lethality was associated with living in a non-endemic country. Actually, estimates of lethality rates ranged from $11 \%$ in the USA [67] to $40 \%$ in the United Kingdom (UK) [68] and 100\% in France [69]. Although healthy adults living in malaria-endemic areas have some immunity to developing clinical malaria, making them able to harbour low levels of parasites without developing clinical symptoms, the recipients of blood transfusions are predominantly patients with severe co-morbidities who are likely to be immunologically compromised. Malaria diagnosis in non-endemic countries where local doctors are not routinely exposed to the disease constitutes a major challenge and requires trained clinical and laboratory personnel [5]. In the absence of early diagnosis and opportune treatment, TT malaria patients may often evolve to poor outcomes. In addition, about $20 \%$ of the TT malaria patients in this study presented long incubation periods (more than 3 months), rendering diagnosis even more difficult due to a more improbable association with transfusion.

Plasmodium falciparum TT malaria was associated with higher lethality in comparison with $P$. malariae and $P$. vivax. Complex systemic disorder triggered by host inflammatory responses is present in all types of malaria. However, in falciparum malaria there is prominent adhesion and vascular sequestration, leading more frequently to severe disease and death [70]. In Latin American countries where $P$. vivax predominates, there is an assumption that vivax malaria is more benign and therefore TT malaria is not considered an important burden to public health [19]. Interestingly, in this work, severity and lethality were also observed for $P$. malariae and $P$. vivax malaria. Especially amongst patients with co-morbidities which are characteristic of transfusion recipients, $P$. vivax is associated with severe disease $[6,8]$.

Complications from neoplasias were associated with a higher odd of lethality from TT malaria in comparison with other transfusion indications. Patients undergoing cancer treatment are commonly under immunosuppressive therapy and frequently need blood transfusion due to anaemia episodes from chemotherapy.
Transfusion-transmitted malaria in patients with neoplastic diseases increases the risk of severe clinical picture and fulminant evolution, regardless of the Plasmodium species [61, 71-73]. In cancer patients, even those at early stages, several coagulation abnormalities lead to an increased tendency to haemostatic dysfunction [74], directly influencing malaria pathogenesis, including disseminated intravascular coagulation and cerebral malaria [75]. Baseline coagulation disorders triggered by neoplastic disease may play a key role in developing malaria complications. Considering that TT malaria in a patient with cancer (and possibly other severe co-morbidities) is always a life-threatening condition, malaria diagnosis must always be considered in patients with a post-transfusion febrile illness. In these cases, however, it is difficult to define the immediate cause of death to malaria rather than the underlying condition.

\section{Conclusions}

The burden imposed by TT malaria in most countries of Latin America with endemic malaria remains a critical knowledge gap. Without this information, it is impossible to estimate whether pre-transfusion screening within endemic settings is a cost-effective option for prevention of TT malaria. Furthermore, there is no screening method available that is practical, affordable and sensitive enough for use by blood banks in American countries where $P$. vivax, a species associated with relapsing episodes and low-level parasitaemia, contributes greatly to transmission. Most available malaria tests, even those based on DNA amplification, may still have limited sensitivity to detect very low levels of parasites (enough to lead to TT malaria), and there is no evidence-based guidance to indicate which malaria screening methods are effective for use by transfusion services in malaria-endemic countries. It is difficult to estimate the incidence of TT malaria among people residing in endemic areas, especially due to TT malaria cases misclassification in populations continuously exposed to vectors, which may lead to a serious underestimation of TT malaria cases. Lethality associated with TT malaria is not negligible, and correlated with living in non-endemic countries when $P$. falciparum was the causative agent and neoplastic diseases were the transfusion indication. In the current context of malaria transmission in Latin America, uncommon ways of transmission regain attention, such as TT malaria, a potential vehicle for parasite re-introduction in areas moving towards elimination. In the absence of a realistic estimate of TT malaria burden, a possible cost benefit analysis of molecular screening or other more sensitive tests in blood donor candidates compared to TT malaria healthcare-associated costs remains a major gap in the literature (Additional file 1). 


\section{Additional file}

Additional file 1. Epidemiological and clinical characteristics of transfusion-transmitted malaria cases reported in the American continent: a systematic review database.

\section{Abbreviations}

API: annual parasite index; Cl: confidence interval; DNA: deoxyribonucleic acid; IIF: indirect immunofluorescence; LAMP: loop-mediated isothermal amplification; LILACS: Latin America and the Caribbean Health Sciences Literature; MEDLINE: Medical Literature Analysis and Retrieval System Online; MeSH: Medical Subject Heading; NAT: nucleic acid testing; OR: odds ratio; PCR: polymerase chain reaction; RBC: red blood cell; RDT: rapid diagnostic test; TT: transfusion-transmitted; USA: United States of America; WHO: World Health Organization.

\section{Authors' contributions}

RMA, KVAM and FFAV carried out the literature search and wrote the first draft of the manuscript. NAF, WMM and MVGL conceived the project. WMM and GCM performed the statistical analysis. MAA, RMA, KVAM, FFAV, GCM, JR, and AMS wrote the final manuscript. All authors read and approved the final manuscript.

\section{Author details \\ 1 Universidade do Estado do Amazonas, Av. Pedro Teixeira, 25, Dom Pedro, Manaus, AM 69040-000, Brazil. ${ }^{2}$ Fundação de Hematologia e Hemoterapia do Amazonas, Av. Constantino Nery, 4397, Chapada, Manaus, AM 69050-002, Brazil. ${ }^{3}$ Fundação de Medicina Tropical Dr. Heitor Vieira Dourado, Av. Pedro Teixeira, 25, Dom Pedro, Manaus, AM 69040-000, Brazil. ${ }^{4}$ Recife, PE, Brazil. ${ }^{5}$ Instituto Nacional de Infectologia Evandro Chagas, Fundação Oswaldo Cruz, Av. Brasil, 4365, Manguinhos, Rio de Janeiro, RJ 21040-360, Brazil. ${ }^{6}$ Instituto de Pesquisas Leônidas \& Maria Deane, Fundação Oswaldo Cruz, Rua Terezina, 476, Adrianópolis, Manaus, AM 69057-070, Brazil.}

\section{Acknowledgements}

Not applicable.

\section{Competing interests}

The authors declare that they have no competing interests.

\section{Availability of data and materials}

All data generated or analysed during this study are included in this published article and its additional information files.

\section{Funding}

No specific funding was received for this work.

Received: 6 January 2017 Accepted: 6 February 2017

Published online: 15 February 2017

\section{References}

1. WHO. World malaria report 2015. Geneva: World Health Organization; 2016

2. Gething PW, Elyazar IRF, Moyes CL, Smith DL, Battle KE, Guerra CA, et al. A long neglected world malaria map: Plasmodium vivax endemicity in 2010. PLoS Negl Trop Dis. 2012;6:e1814.

3. Bhatt S, Weiss DJ, Cameron E, Bisanzio D, Mappin B, Dalrymple U, et al. The effect of malaria control on Plasmodium falciparum in Africa between 2000 and 2015. Nature. 2015:526:207-11.

4. Oliveira-Ferreira J, Lacerda MVG, Brasil PP, Ladislau JJLB, Tauil PL, DanielRibeiro CCT. Malaria in Brazil: an overview. Malar J. 2010:9:115.

5. de Pina-Costa A, Brasil P, Di Santi SM, de Araujo MP, Suárez-Mutis MC, Santelli AC, et al. Malaria in Brazil: what happens outside the Amazonian endemic region. Mem Inst Oswaldo Cruz. 2014;109:618-33.

6. Siqueira AM, de Lacerda MVG, Magalhães BML, Mourao MPG, Melo GC, Alexandre MAA, et al. Characterization of Plasmodium vivax-associated admissions to reference hospitals in Brazil and India. BMC Med. 2015;13:57.

7. Baird JK. Evidence and implications of mortality associated with acute Plasmodium vivax malaria. Clin Microbiol. 2013;26:36-57.

8. Lacerda MV, Mourão MP, Alexandre MA, Siqueira AM, Magalhães BM, Martinez-Espinosa FE, et al. Understanding the clinical spectrum of complicated Plasmodium vivax malaria: a systematic review on the contributions of the Brazilian literature. Malar J. 2012;11:12

9. Ministério da Saúde do Brasil. Boletim Epidemiológico-Situação epidemiológica da malária no Brasil, 2012 e 2013. Brasília: Ministério da Saúde do Brasil; 2015

10. Alexandre MA, Ferreira CO, Siqueira AM, Magalhães BL, Mourão MPG, Lacerda MV, et al. Severe Plasmodium vivax malaria Brazilian Amazon. Emerg Infect Dis. 2010;16:1611-4.

11. Siqueira AM, Alexandre MAA, Mourão MPG, Santos VS, Nagahashi-Marie SK, Alecrim MGC, et al. Severe rhabdomyolysis caused by Plasmodium vivax malaria in the Brazilian Amazon. Am J Trop Med Hyg. 2010;83:271-3.

12. Pinzón MA, Pineda JC, Rosso F, Shinchi M, Bonilla-Abadía F. Plasmodium vivax cerebral malaria complicated with venous sinus thrombosis in Colombia. Asian Pac J Trop Med. 2013:6:413-5.

13. Quispe AM, Pozo E, Guerrero E, Durand S, Baldeviano GC, Edgel KA, et al. Plasmodium vivax hospitalizations in a monoendemic malaria region: severe vivax malaria? Am J Trop Med Hyg. 2014;91:11-7.

14. Saleri N, Gulletta M, Matteelli A, Caligaris S, Tomasoni LR, Antonini B, et al. Acute respiratory distress syndrome in Plasmodium vivax malaria in traveler returning from Venezuela. J Travel Med. 2006;13:112-3.

15. Lacerda MVG, Fragoso SCP, Alecrim MGC, Alexandre MAA, Magalhaes $B M L$, Siqueira AM, et al. Postmortem characterization of patients with clinical diagnosis of Plasmodium vivax malaria: to what extent does this parasite kill? Clin Infect Dis. 2012;55:e67-74.

16. Ministério da Saúde do Brasil. Resolução-RDC n153, de 14 de Junho de 2004. Brasília: Ministério da Saúde do Brasil; 2004

17. Ministério da Saúde do Brasil. Marco Conceitual e Operacional de Hemovigilância: Guia para a Hemovigilância no Brasil. Brasília: Ministério da Saúde do Brasil; 2015.

18. Freitas DRC, Duarte EC. Normative evaluation of blood banks in the Brazilian Amazon region in respect to the prevention of transfusiontransmitted malaria. Rev Bras Hematol Hemoter. 2014:36:394-402.

19. Lacerda MVG, Monteiro WM, Alexandre MAA, Alho RRM, Kiesslich D, Fraiji NA. We need to talk more about transfusion-transmitted malaria in Plasmodium vivax endemic areas. Rev Bras Hematol Hemoter. 2014;36:385-7.

20. Pagano M, Gauvreau K. Principles of Biostatistics. 2nd ed. Belmont: Brooks/Cole; 2000.

21. Deeks J, Higgings J. Statistical algorithms in Review Manager 5. 2010. http://ims.cochrane.org/revman/documentation/Statistical-methods-inRevMan-5.pdf. Accessed 12 Mar 2015.

22. Castillo C, Ramírez C. Tamización de malaria en donantes de sangre de Cali, Colombia. Biomédica. 2005;25:203-10.

23. Katz LM, Kabat A. Return behavior of blood donors after expiration of a 1-year malarial travel deferral. Transfusion. 2007;47:356-7.

24. Leiby DA, Nguyen ML, Notari EP. Impact of donor deferrals for malaria on blood availability in the United States. Transfusion. 2008;48:2222-8.

25. O'Brien SF, Fan W, Xi G, Yi QL, Fearon M, Goldman M. Donor loss due to malaria-risk travel deferral. Transfusion. 2008;48:62A.

26. O'Brien SF, Uzicanin S, Choquet K, Yi QL, Fan W, Goldman M. Impact of changes to policy for Mexican risk travel on Canadian blood donor deferrals. Blood Transfus. 2013:11:580-4

27. Sáez-Alquézar A, Ramos AM, Di Santi SM, Branquinho MS, Kirchgatter K, Cordeiro IA, et al. Control of blood transfusion malaria in an endemic and in a non-endemic region in Brazil. Rev Soc Bras Med Trop. 1998;31:27-34.

28. Shehata N, Kohli M, Detsky A. The cost-effectiveness of screening blood donors for malaria by PCR. Transfusion. 2004:44:217-28.

29. Spencer BR, Custer B, Kakaiya R, Hillyer K, Wilkinson SL, Gottschall J. Low risk for malaria transmission from presenting blood donors excluded for travel to Mexico. Transfusion. 2006;46:27A

30. Spencer B, Steele W, Custer B, Kleinman S, Cable R, Wilkinson S, et al. Risk for malaria in United States donors deferred for travel to malaria-endemic areas. Transfusion. 2009:49:2335-45.

31. Spencer B, Kleinman S, Custer B, Cable R, Wilkinson SL, Steele W, et al. Deconstructing the risk for malaria in United States donors deferred for travel to Mexico. Transfusion. 2011:51:2398-410. 
32. Torres KL, Figueiredo DV, Zalis MG, Daniel-Ribeiro CT, Alecrim W, Ferreirada-Cruz MF. Standardization of a very specific and sensitive single PCR for detection of Plasmodium vivax in low parasitized individuals and its usefulness for screening blood donors. Parasitol Res. 2006;98:519-24.

33. Torres K, Moresco MNDS, Sales LR, Abranches JDS, Alexandre MAA, Malheiro A. Transfusion-transmitted malaria in endemic zone: epidemiological profile of blood donors at the Fundação HEMOAM and use of rapid diagnostic tests for malaria screening in Manaus. Rev Bras Hematol Hemoter. 2014;36:269-74

34. Nguyen ML, Goff T, Gibble J, Steele WR, Leiby DA. Analyzing actual risk in malaria-deferred donors through selective serologic testing. Transfusion. 2013;53:1736-43

35. Maselli LMF, Levy D, Laporta GZ, Monteiro AM, Fukuya LA, Ferreira-daCruz MF, et al. Detection of Plasmodium falciparum and Plasmodium vivax subclinical infection in non-endemic region: implications for blood transfusion and malaria epidemiology. Malar J. 2014;13:224

36. Contreras CE, de Donato M, Rivas MA, Rodulfo H, Mora R, Batista ME, et al. Malaria seroprevalence in blood bank donors from endemic and nonendemic areas of Venezuela. Mem Inst Oswaldo Cruz. 2011;106:123-9.

37. Nunez L, Linares J, Perez AH. Seroprevalence of antibodies against Plasmodium falciparum in volunteer donors from various cities in Venezuela. Sangre. 1992;37:141-3.

38. de Morales PO, Espinal CA. Deteccion de anticuerpos antiplasmodium por ELISA en donantes de sangre. Biomedica. 1982;2:57-62.

39. Contreras CE, Pance A, Marcano N, Gonzalez N, Bianco N. Detection of specific antibodies to Plasmodium falciparum in blood bank donors from malaria-endemic and non-endemic areas of Venezuela. Am J Trop Med Hyg. 1999;60:948-53.

40. de Olaya MP, Duque E, Espinal CA, Guerra P. Application of the ELISA method in the detection of malaria antibodies in blood donors. Pan Am J Public Health. 1986;101:348-54.

41. Ferreira MU, Camargo LMA, de Carvalho ME, Ninomia RT, Garcia LAV, dos Santos FR. Prevalence and levels of lgG and lgM antibodies against Plasmodium falciparum and P. vivax in blood donors from Rondônia, Brazilian Amazon. Mem Inst Oswaldo Cruz. 1993;88:263-9.

42. Batista-dos-Santos S, Raiol M, Santos S, Cunha MG, Ribeiro-dos-Santos A. Real-time PCR diagnosis of Plasmodium vivax among blood donors. Malar J. 2012;11:345.

43. Fugikaha É, Fornazari PA, Rde Penhalbel SR, Lorenzetti A, Maroso RD, Amoras JT, et al. Molecular screening of Plasmodium sp. asymptomatic carriers among transfusion centers from Brazilian Amazon region. Rev Inst Med Trop Sao Paulo. 2007:49:1-4.

44. Sulzer AJ, Wilson M. The indirect fluorescent antibody test for the detection of occult malaria in blood donors. Bull World Health Organ. 1971:45:375-9.

45. WHO. Blood transfusion safety: testing of donated blood. Geneva: World Health Organization; 2009.

46. Mueller I, Galinski MR, Baird JK, Carlton JM, Kochar DK, Alonso PL, et al Key gaps in the knowledge of Plasmodium vivax, a neglected human malaria parasite. Lancet Infect Dis. 2009;9:555-66.

47. Greenwood T, Vikerfors T, Sjoberg M, Skeppner G, Farnert A. Febrile Plasmodium falciparum malaria 4 years after exposure in a man with sickle cell disease. Clin Infect Dis. 2008;47:e39-41.

48. Szmitko PE, Kohn ML, Simor AE. Plasmodium falciparum malaria occurring 8 years after leaving an endemic area. Diagn Microbiol Infect Dis. 2009:63:105-7.

49. Theunissen C, Janssens P, Demulder A, Nouboussie D, Van-Esbroeck M, Van-Gompel A, et al. Falciparum malaria in patient 9 years after leaving malaria-endemic area. Emerg Infect Dis. 2009;15:115-6.

50. Vinetz JM, Li J, McCutchan TF, Kaslow DC. Plasmodium malariae infection in an asymptomatic 74-year-old Greek woman with splenomegaly. N Engl J Med. 1998;338:367-71.

51. Ashley EA, White NJ. The duration of Plasmodium falciparum infections. Malar J. 2014;13:500

52. Nansseu JRN, Noubiap JJN, Ndoula ST, Zeh AFM, Monamele CG. What is the best strategy for the prevention of transfusion-transmitted malaria in sub-Saharan African countries where malaria is endemic? Malar J. 2013;12:465.
53. Mendrone AM Jr, Cerutti C Jr, Levi JE, Boulos M, Sanchez MCA, Malafronte RS, et al. Unexpected detection of Plasmodium vivax and Plasmodium falciparum DNA in asymptomatic blood donors: fact or artifact? Malar J. 2014; 13:336.

54. Surabattula R, Vejandla MP, Mallepaddi PC, Faulstich K, Polavarapu R. Simple, rapid, inexpensive platform for the diagnosis of malaria by loop mediated isothermal amplification (LAMP). Exp Parasitol. 2013;134:333-40

55. Hofmann N, Mwingira F, Shekalaghe S, Robinson LJ, Mueller I, Felger I. Ultra-sensitive detection of Plasmodium falciparum by amplification of multi-copy subtelomeric targets. PLoS Med. 2015;12:e1001788.

56. de Freitas DRC, Gomes LT, Fontes CJF, Tauil PL, Pang LW, Duarte EC. Sensitivity of nested-PCR for Plasmodium detection in pooled whole blood samples and its usefulness to blood donor screening in endemic areas. Transfus Apher Sci. 2014;50:242-6.

57. Versiani FG, Almeida MEM, Melo GC, Versiani FOL, Orlandi PP, Mariuba LAM, et al. High levels of IgG3 anti ICB2-5 in Plasmodium vivax-infected individuals who did not develop symptoms. Malar J. 2013:12:294.

58. Owusu-Ofori AK, Betson M, Parry CM, Stothard JR, Bates I. Transfusiontransmitted malaria in Ghana. Clin Infect Dis. 2013:56:1735-41.

59. Garfield MD, Ershler WB, Maki DG. Malaria transmission by platelet concentrate transfusion. JAMA. 1978:240:2285-6.

60. Dover AS, Guinee VF. Malaria transmission by leukocyte component therapy. JAMA. 1971;217:1701-2.

61. Najem GR, Sulzer AJ. Transfusion-induced malaria from an asymptomatic carrier. Transfusion. 1976;16:473-6.

62. Grellier P, Benach J, Labaied M, Charneau S, Gil H, Monsalve G, et al. Photochemical inactivation with amotosalen and long-wavelength ultraviolet light of Plasmodium and Babesia in platelet and plasma components. Transfusion. 2008;48:1676-84

63. Allain J-P, Owusu-Ofori AK, Assennato SM, Marschner S, Goodrich RP, Owusu-Ofori S. Effect of Plasmodium inactivation in whole blood on the incidence of blood transfusion-transmitted malaria in endemic regions: The African investigation of the Mirasol system (AIMS) randomised controlled trial. Lancet. 2016;387:1753.

64. Chadee DD, Tilluckdharry CC, Maharaj P, Sinanan C. Reactivation of Plasmodium malariae infection in a Trinidadian man after neurosurgery. N Engl J Med. 2000;342:1924.

65. Siala E, Khalfaoui M, Bouratbine A, Hamdi S, Hili K, Aoun K. Relapse of Plasmodium malariae malaria 20 years after living in an endemic area. Presse Med. 2005;34:371-2.

66. Tsuchida H, Yamaguchi K, Yamamoto S, Ebisawa I. Quartan malaria following splenectomy 36 years after infection. Am J Trop Med Hyg. 1982;31:163-5.

67. Mungai M, Tegtmeier G, Chamberland M, Parise M. Transfusion-transmitted malaria in the United States from 1963 through 1999. N Engl J Med. 2001;344:1973-8.

68. Kitchen AD, Barbara JAJ, Hewitt PE. Documented cases of post-transfusion malaria occurring in England: a review in relation to current and proposed donor-selection guidelines. Vox Sang. 2005;89:77-80.

69. Garraud O, Assal A, Pelletier B, Danic B, Kerleguer A, David B, et al. Overview of revised measures to prevent malaria transmission by blood transfusion in France. Vox Sang. 2008:95:226-31.

70. Mackintosh CL, Beeson JG, Marsh K. Clinical features and pathogenesis of severe malaria. Trends Parasitol. 2004;20:597-603.

71. Dodin A, Damas A, Andriamiandra A. A propos de deux cas de leucémie traités au chloraminophène ayant révélé un paludisme latent. Bull Soc Pathol Exot. 1969;62:867.

72. Tapper ML, Armstrong D. Malaria complicating neoplastic disease. Arch Intern Med. 1976;136:807-10.

73. Duperval R, Longpre B, Madarnas P. Unexplained falciparum malaria in a patient with chronic lymphocytic leukemia. Can Med Assoc J. 1979;121:1585-8

74. Falanga A, Marchetti M, Vignoli A. Coagulation and cancer: biological and clinical aspects. J Thromb Haemost. 2013;11:223-33.

75. O'Sullivan JM, Preston RJS, O'Regan N, O'Donnell JS. Emerging roles for hemostatic dysfunction in malaria pathogenesis. Blood. 2016;127:2281-8. 